\title{
The Artistic Function of the Remarque Genre in Karakalpak Comedy
}

\author{
R. Z. Matmuratova ${ }^{1}$ \\ ${ }^{1}$ Researcher Nukus State Institute named after Ajiniyaz. \\ Uzbekistan
}

\begin{abstract}
:
In the given article the problems of artistic and aesthetic functions of the main compositional unit of the comedy genre are investigated. The theoretical side of the problem is analyzed on the example of comedies of Karakalpak playwrights. For the first time in Karakalpak literary criticism, a conclusion has been made about the problem of artistic classification of a remark. The article explores such artistic functions of the remarks as the actions of the hero and the formation of the external compositional structure of the work. The comedies of D.Aytmuratov and M. Nizanov were analyzed on determining the theoretical result of the remark. The problem of internal and external remarks was first implemented into the science of Karakalpak literature. The studied problem is based; theoretical solutions and proposals are given.
\end{abstract}

Key words: drama, comedy, note, gesture-emotion note, gesture-intonation note, author-account note

Article Received: 16th October, 2020; Article Revised: 30th December, 2020; Article Accepted: 08th January, 2021

\section{Introduction}

Each genre has specific compositional elements. The remark is an important compositional element of the drama genre. The director stages the drama, and the actor performs. The action in the play consists of the beginning, the development, the climax, the conclusion of which turn into a dialogue and a monologue of the characters. But if we limit ourselves only to the dialogues of the characters, we can detect a decline in the artistic and aesthetic power of the drama. Therefore, you need to animate a variety of colors and give a palette of colors of different shades. To do this, the actors must use the necessary required elements (rhythm, facial expressions, gesture movements, pause, etc.). The required elements show the psychological state of the image, and such contributes to the disclosure of a personal character. "From an artistic point of view, the problem lies in the inner harmony, the proportionality of the "direct" and "indirect" image of the various phases of the dramatic action, the unity of its "scale". These phases do not always coincide with what in the language of the theory of drama, its technology is

usually called the exposition, the beginning, the climax and the denouement (and even more so with the division of the play into acts) [1:156]. How the author conveys the artistry of such features.

\section{The main results and findings}

The playwright must limit himself to the artistic description of the idea. He should briefly, in a nutshell, convey, say, a landscape or when creating a portrait of a hero. The remark is a compositional element that saves the playwright in such a difficult situation. "Remark (Fr. remarqueremark, explanation) - an indication of the author in the text of the play (usually in brackets) on the actions of the characters, their gestures, facial expressions, intonation, the psychological meaning of their statements, the tempo of speech and pauses, the situation of the action" [2:870]. A remark is an artistic element that describes the place, time, state of the character, etc. If we pay attention to the artistic and creative relationship between the playwright and the actor, we can find that the only main means of artistic reflection of the image on the stage is a remark. The degree of conscious psychotechnical overcoming of the actor's remarks determines his degree of correct performance of the role "The correctness of the performance of the role is a logical, consistent truth-telling reasoning, 
movement when performing a role on stage (3:27). Recently, in the Karakalpak drama, the remark is conveyed in a short form, than its subject books or whose parts are missing. For example, in M. Nyzanov, the remark is expressed briefly or in an omitted form. The remark, according to Sakhnovsky-Pankeev, is a component introduced by the history of the development of drama. In ancient Greece, they are not present, in Shakespeare - at least, the further, the more the remarks appear more often and become more and more extensive [4: 40].

The artistic function of the remark in dramatic works draws the attention of B.Imamov, who connects it with the function of reflection with the biography of characters, gestures, movements, facial expressions [5]. A. I. Rustamova points to such types of remarks as the description of the place, movement, state, psychologism according to genre features [6].

The main functions of the remark can be considered as:

- commenting;

* reporting additional conditions;

* clarifying the meaning;

* indication of locations of action;

* indication of the validity period;

* disclosure of the psychological state;

* indication of simultaneity.

Remark system:

1. Remarks characteristics ("in a jacket", " in boots»);

2. Gesture-body movements in a confined space.

a) household function ("tying the napkin»);

b) the characterizing function.

c) expressive and dramatic functions ("pulling out the hand").

3. Gesture-emotional ("crying", "laughing").

4. Speech-intonation ("joyfully", "irritated").

5. Gesture-intonation ("interrupting", "teasing").

6. Mise-en-scene.

7. Paused.

8. Leaving / entering of the character.
9. The addressee of the remark ("to the servant").

10. Emotional nature ("in indignation").

11. Performing an action ("rests his hands", " slams the door, reads the letter» Physical condition ("out of breath").

13. The scene of action.

14. Validity period.

15. Storylines.

16. Scenographic (situational).

17. Service remarks (indicating various stage techniques).

18. Literary and narrative ("the city is not visible, but only in good weather").

19. Paused (some refer to the play of actors, others to director):

- backlash pause in speech (expressed by a three-dot);

- a stop in speech production (as a sign of difficulty);

- as a stop in action ("pause»);

- semantic pause;

- as a wordless action;

- as a director's technique;

- teichoscopy pauses [4: 40].

In the work" The Inspector" by Gogol, which has become a classic comedy in world literature, comments are given to the actors about the characters and costumes of the characters and thus form the basis of the text for a real stage work. "The mayor, who has already aged in the service and is very intelligent in his own way, Although a bribe-taker, but behaves very solidly; he is quite serious; he is even somewhat reasonable; speaks neither loudly nor quietly, neither much nor little. His every word is significant. His facial features are coarse and tough, like those of anyone who began his service from the lowest ranks. The transition from fear to joy, from rudeness to arrogance, is quite rapid, as in a person with rudely developed inclinations of the soul. He is dressed, as usual, in his uniform with buttonholes and boots with spurs. His hair is cropped with gray " [7: 4]. If we conditionally call the internal remark to the author's speech, then we can call the external remark the author's description outside the plot, since 
both are the author's explanation. Such remarks for the actors are written to be an example for an external remark in the comedy "The Inspector". In this way, the playwright loads the performance function on the remark. This interpretation gives the director the opportunity for a better dramatization of the comedy. This explanation is the main factor in turning the work into a classic comedy. N. V.Gogol's remarks became the impetus for the full coverage of the dynamics of time. Such remarks as "pointing to the top with his finger", "waving his hand around his head", "showing a clenched fist to the side" completely merge into the time action. There are many such examples in the "The Inspector". We would like to see this phenomenon also in the Karakalpak comedy. We justify ourselves by the fact that A. Utegenov, Zh. Aimurzaev, K. Avezov, A. Begimov and others are among the first playwrights and it is quite natural that their works may have compositional flaws. But all this is a big drawback. We must agree that there are errors in their works that do not correspond to the text of the drama, not to mention the remark. However, the subsequent time can be seen in the harmony of the remark with the time of action in the works of K. Rakhmanov, S. Zhumagulov, M. Nyzanov and U. Abdurakhmanov in connection with the development of Karakalpak drama. If in some dramatic work there are no wordless movements, then remarks are often used. In the comedy "Ekstrasens (Psychic)" by S. Zhumagulov, we can see wonderful examples of remarks. (Unfortunately, the real comedy has not yet been reprinted). In the work, the actions of the characters dynamically develop along with the dialogue. The artistic function of the remark is important here.

Kalbay: - You'll see, you'll feel it now! (He quietly takes the iron from under the bed and inserts it into the electric socket. This way, he quietly holds the iron closer to his back.
Jollyball: No! I mean, yes, it feels warm. Yes, it's still hot (Shouting). Yes!Yes! You have bioenergy! Ah, how good they are! May the Lord protect you! (He is enjoying himself and lies very contented.)

Kalbi:- (bringing it closer) Well, now you're a journalist, tell me! Were you finally convinced that I had a gift?

Jollyball: -more as well! Yes! Yes! [8: 27]

On this episode, the remark is loaded with the function transferred to the action. The first remark of the autorec is narrative, that is, it is limited only to the observation of the external action of the character. The second is a gesture-emotional remark. It is transmitted to indicate a sense of delight and surprise. The third remark is a gestureintonation, which shows the character's prolonged actions before and after the process. The fourth-the author's-narrative, that is, also conveys the actions of the character that should occur: In such remarks, despite the fact that there is no emotion, they are loaded with the function of a more perfect disclosure of the character's nature.

Only live action generates drama. For this reason, gesture-emotional and gestureintonation remarks are often used.

A gesture-emotional remark is a reflection of the emotional actions taking place in the psychology of the character. If one of the main conditions of the comedy genre is the transmission of dialogue and action in a humorous and satirical pathos, then the remarks serve as an element that ensures the fulfillment of this condition.

Baynazarov Koshkarbai: - (hitting his head with a fist addresses Matsapaev Dosmurza and Tilepbai). Have you just grieved over your unhappy fate?!

Matsapaev Tilepbai: Yes, we have just grieved over our unfortunate fate!

Baynazarov Koshkarbai: - If so, then it is really very difficult for us, to overthrow our banner!!! (Sobs bitterly, banging his head with his fist) [10: 217].

If there were no remark in the above lines, then the feelings of Baynazarov Koshkarbai would not be revealed. With 
the help of a remark, a bitter lament and self-condemnation are narrated in connection with the sudden death of his boss Pirkakkan. The viewer does not awaken a feeling of pity for Baynazarov Koshkarbay, but rather a grin at his stupidity. As mentioned above, in comedy, dialogue (monologue, prologue) and actions are subordinated to humorous and satirical pathos. Of course, actions of Baynazarov Koshkarbai generates no to tragedy, but to Comedy. Because, he accepts the death. Pirkakkan Urakova is who brought our society into a crisis situation with great sympathy. This led to be witness the bitter truth on stage. The author managed to subordinate the gestureemotional remark to all the requirements of the comedy genre.

Gesture-intonation remark occurs as a result of the fusion of action and intonation. The character showing both actions and intonations at the same time together, contributes to the appearance of a gesture-intonation remark. And again we turn to the "The Inspector":

"The mayor in the middle is in the form of a pillar, with his arms outstretched and his head thrown back. On the right hand of his wife and daughter with a movement of the whole body rushing towards him; behind them, the postmaster who turned into a question mark, addressed to the audience; behind him, Luka Lukich, lost in the most innocent way; behind him, at the edge of the stage, the three ladies, guests, leaning against one another with the most satirical expression on their face, related directly to the family of the mayor. On the left side of the mayor: Strawberry, tilting his head slightly to one side, as if listening to something; behind him, the judge with his arms outstretched, crouched almost to the ground and made a movement with his lips, as if he wanted to whistle or say: "Here you are, grandma and St. George's Day!" [7: 47].

\section{Main part}

No action or voice is involved in this phenomenon. Only the gesture movements of the remark, that is, the interrupted situation in the action by the character is here. "The final words of the drama should remind us that its task is not to depict an accidental, once-occurring event, but a truly poetic one, which has a universal meaning that is understandable to all" [9: 120]. This scene gives the sharpness of the decision of "The Inspector".

Bainazarov Koshkarbai and Tanatarov Yaumytbai are sobbing bitterly, Mambetsadaev Akkokirek aha with Aimereke Akkatyn are also crying. The wife of Pirkakkan Urakov, Akbozlakhanim, together with her lover Aktamak-ayim, are crying secretly. Utegenov Ismayil, Matsapayev Dosmurza, Tilepbay and others are not very bitter, but with tears in their eyes, because they will not be able to cry bitterly as a woman's appearance, without any speeches, only on actions and voices. In this scene, there are only the movements and they continue the actions. In this duration, the gestureintonation actions of the characters merge with the content of the action.

Studying the artistic function of the remark in drama, we come to the following decision: It is

It's advisable to distinguish between the external and internal remark before or after the beginning of the action. Because there is a difference in their artistic functions. The external remark is limited only by the general characteristic of the character. For example, it is responsible for giving information about its character, appearance, and clothing.

We have briefly focused on the gestureemotional, gesture-intonation, authornarrative remark in the Karakalpak comedy.

1. Author-narrative remark-limited only to the presentation of the action by the authors shows any action necessarily performed by the character on the stage.

2. The gesture-emotional remark is justified by the reflection of the emotional 
actions taking place in the psychology of the character.

\section{Conclusion}

Gesture-intonation remark occurs through the fusion of movement and intonation. It will be passed for scenes showing the intonation of the character between any actions.

\section{References}

[1] Karyagin A.A. Drama as an aesthetic problem. Moscow. "Nauka". 1971.

[2] Literary encyclopedia of terms and concepts. Editor-in-Chief and compiler AN Nikolyukin. Moscow. NPK "Intelvak". 2001.

[3] Stanislavsky K.S. The actor's working on himself. The first part. Tashkent. Yangi asr avlodi. 2011.

[4] I.N.Chistyukhin. About drama and dramaturgy. Moscow. eBook. 2002.

[5] Imomov B. Secrets of dramatic skill. Tashkent. Ghafur Ghulam nomidagi Nashriyot-matbaa birlashmasi. 1991.

[6] Rustamova I. The problem of heroism in Uzbek drama (70-80s). Ph.D. Tashkent. 1999.

[7] Gogol N.V. Collection of essays in seven volumes. Volume 4. Dramatic works: Khudojestvennaya literatura; Moscow; 1977

[8] Zhumagulov S. Psychics. Author's home archive.

[9] Freitag G. Drama technique. 1863.

[10] Rotterdamskiy E. Praise for stupidity., Aitmuratov D. In a world of stupidity. Nukus. Karakalpakstan. 1990.

[11] Shamshetdinovich, N. A. (2020). Changes In The Socio-Political Vocabulary Of Karakalpak Language. European Journal of Molecular \& Clinical Medicine, 7(6), 2395-2402.
In general, the remark plays an important role in the beginning of the action, the development, the climax as well, and in the path of transmission to the solution. It provides the right and high-quality role that serves as a guide for the director and actor. Of course, the remark is an important compositional element of the life-defining drama on the stage. 